Revista Destaques Acadêmicos, Lajeado, v. 11, n. 4, 2019. ISSN 2176-3070

DOI: http://dx.doi.org/10.22410/issn.2176-3070.v11i4a2019.2352

http://www.univates.br/revistas

\title{
AVALIAÇÃO DE UNIDADES HABITACIONAIS PARA REDUÇÃO DO CONSUMO ENERGÉTICO
}

\author{
Camila Ely ${ }^{1}$, Naiara Fachinelli², Pâmela Wehner ${ }^{3}$, Cassia Zart ${ }^{4}$, \\ Cristiano Zluhan ${ }^{5}$, Rodrigo Spinelli ${ }^{6}$
}

\begin{abstract}
Resumo: Atualmente as edificações são pensadas priorizando a eficiência energética, que consiste em um maior conforto térmico e consequentemente uma significante economia de energia. Para que este conforto seja alcançado, faz-se necessário diminuir a troca de calor entre os ambientes, utilizando materiais que possuem em suas propriedades o isolamento térmico. No presente estudo foram analisados quatro apartamentos com posições geográficas diferentes, situados no último pavimento de uma das torres de um conjunto habitacional na cidade de Lajeado - RS. Comparou-se a carga térmica transmitida pelas paredes das áreas de vivência, cobertura e janelas dos quatro apartamentos, em duas situações: uma com a materialidade original da edificação e outra utilizando isolantes térmicos. Para o isolamento foi utilizado poliestireno expandido (EPS) abaixo do reboco das paredes, janelas de vidro duplo insulado e cobertura de telhas sanduíche com chapas de aço galvanizado e interior de EPS. A análise foi efetuada através de um padrão de cálculos, onde foram determinadas carga térmica e gastos com climatização para as duas situações. Com isso, pôde-se comprovar a eficiência dos materiais isolantes térmicos, que para alguns apartamentos diminuiu os gastos com climatização em até $80 \%$.
\end{abstract}

Palavras-chave: Eficiência energética; Isolamento térmico; Conforto térmico; Carga térmica.

1 Aluno do curso de Engenharia Civil da Universidade do Vale do Taquari - Unitaves.

2 Aluno do curso de Engenharia Civil da Universidade do Vale do Taquari - Unitaves.

3 Aluno do curso de Engenharia Civil da Universidade do Vale do Taquari - Unitaves.

4 Aluno do curso de Arquitetura e Urbanismo da Universidade do Vale do Taquari - Unitaves.

5 Docente do curso de Arquitetura e Urbanismo, Universidade do Vale do Taquari - Univates.

6 Docente dos cursos de Arquitetura e Urbanismo e Engenharia Civil, Universidade do Vale do Taquari - Univates. 


\section{INTRODUÇÃO}

A arquitetura deve servir ao homem e ao seu conforto, o que abrange o conforto térmico. $\mathrm{O}$ homem tem melhores condições de vida e de saúde quando seu organismo pode funcionar sem ser submetido à fadiga ou estresse, inclusive térmico. A arquitetura, tem como uma de suas funções oferecer condições térmicas compatíveis ao conforto térmico humano no interior dos edifícios, sejam quais forem as condições climáticas externas (OLIVEIRA, 2015).

A avaliação do desempenho térmico das edificações consiste na determinação de valores limites para a transmitância e capacidade térmica da envoltória, e um método detalhado, que prevê a realização de simulações computacionais do comportamento térmico do edifício nos dias típicos de projeto para o período de verão e de inverno.

Segundo Goulart (1993), o processo de construir uma edificação adaptada ao clima pode ser dividido em quatro passos, dos quais o último é a expressão arquitetônica. O primeiro passo em direção ao ajuste ambiental é o levantamento de elementos climáticos de um local e a análise destes dados meteorológicos. Sendo o homem a medida fundamental na arquitetura e o abrigo, projetado para satisfazer suas necessidades biológicas, o segundo passo é avaliar cada impacto do clima em termos psicofisiológicos. Como terceiro passo, uma solução tecnológica deve ser aplicada para cada problema confortoclima. Essa solução pode ser obtida por métodos de cálculos, onde se analisam a orientação, necessidade ou não de sombra, forma da edificação, movimento de ar, e ainda balanço de temperatura interna que pode ser conseguido com uso cuidadoso de materiais. No estágio final, estas soluções combinadas de acordo com sua importância, resultam em harmonia arquitetônica.

O clima afeta a execução, a segurança, o conforto e o desempenho de edificações. Portanto, o estudo da climatologia aplicada à construção é imprescindível em todas as fases do projeto arquitetônico, além disso, envolve um processo interativo, onde devem ser levada em conta a influência do clima na edificação e a influência da edificação sobre o clima do entorno (GOULART, 1993).

O empreendimento em estudo encontra-se na cidade de Lajeado - RS, Bairro Centenário localizado na região Geomorfológica Planalto da Araucária, com o clima predominante temperado úmido, consiste em temperaturas médias de $22^{\circ}$. Em períodos de regime de chuvas atinge média anual de 1600 $\mathrm{mm}$, nos dozes meses do ano a direção predominante dos ventos se localizam em coordenadas Norte - Nordeste, Leste - Sudeste e Norte- nordeste. O clima característico da região no verão é de temperaturas altas e tempo seco, inverno frio e úmido. 


\section{MATERIAIS E MÉTODOS}

O estudo analisou os ambientes de permanência de quatro apartamentos situados em uma das torres de um conjunto habitacional de interesse social, localizado na cidade de Lajeado/RS. Conforme destacadas na figura 1, as unidades escolhidas foram: apartamento de 2 dormitórios com posição solar norte e leste (destaque em vermelho); apartamento de 1 dormitório com posição solar leste (verde); apartamento de 3 dormitórios com posição solar sul e oeste (amarelo); apartamento de 2 dormitórios com posição solar oeste (rosa).

A determinação de distribuição térmica das unidades escolhidas foi verificada através de duas situações: situação 1 , com a materialidade original da edificação; e situação 2, trazendo a proposta de isolamento térmico. $\mathrm{O}$ conjunto habitacional caracteriza-se por alvenaria estrutural, a materialidade original conta com paredes de blocos estruturais de concreto $(15 \times 19 \times 29 \mathrm{~cm})$; aberturas de vidro simples $(3 \mathrm{~mm}$ ); e cobertura com laje de concreto armado e telhas de fibrocimento. Para a situação com isolamento térmico utilizou-se para as paredes placas de poliestireno expandido, com $5 \mathrm{~cm}$ de espessura sob o reboco, e para a cobertura telhas sanduíche de chapa de aço galvanizado com interior de poliestireno. 
Figura 1- Planta baixa dos apartamentos

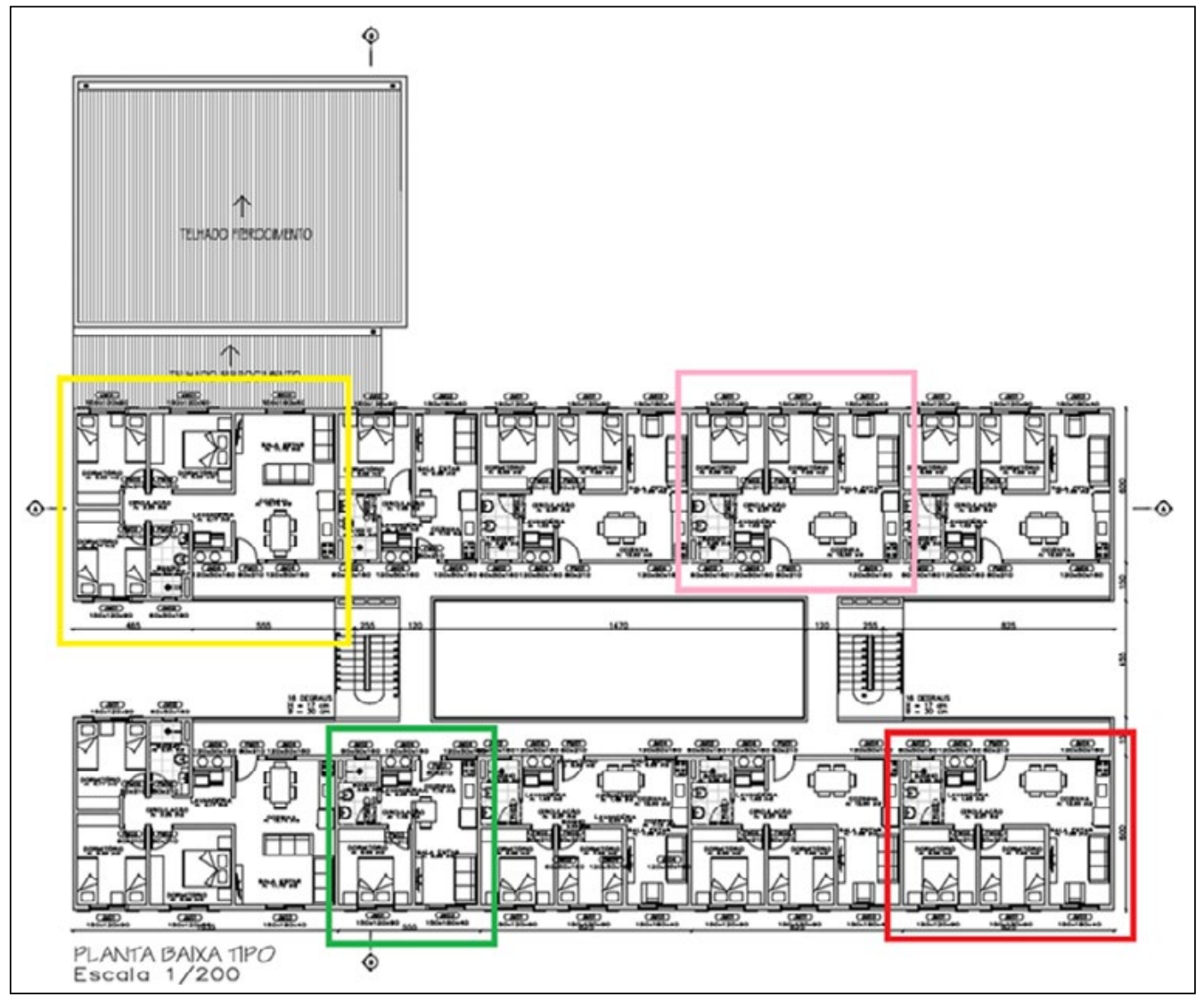

Fonte: Dos autores(2019).

\subsection{Resistência Térmica e Transmitância}

Segundo a NBR 15220 (ABNT, 2003), resistência térmica total de um fechamento $\left(\mathrm{R}_{\mathrm{T}}\right)$, equação 1 , consiste no somatório da resistência térmica da materialidade $(R)$, resistência térmica interna $\left(R_{s i}\right)$ e resistência térmica externa

$\left(R_{s e}\right)$. Para $R_{s i}$ e $R_{s e}$ a norma citada traz valores tabelados conforme direção do fluxo de calor. Para R são descritos cálculos onde a condutividade térmica $(\lambda)$ é relacionada à espessura de cada material, conforme equação 2 .

$$
\mathrm{R}_{\mathrm{T}}\left(\mathrm{m}^{2} \cdot \mathrm{K}\right) / \mathrm{W}=\mathrm{R}_{\mathrm{t}}+\mathrm{R}_{\mathrm{si}}+\mathrm{R}_{\mathrm{se}}
$$

Onde:

RT: resistência térmica total; 
$\mathrm{R}$ : resistência térmica do fechamento, $\mathrm{m}^{2} . \mathrm{K} / \mathrm{W}$;

$\mathrm{R}_{\mathrm{si}}$ : resistência superficial interna-fluxo de calor descendente $=0,17 \mathrm{~m}^{2}$. $\mathrm{K} / \mathrm{W}$, conforme NBR 15220 (ABNT, 2003);

$R_{s e}$ : resistência superficial externa-fluxo de calor descendente $=0,04 \mathrm{~m}^{2}$. $\mathrm{K} / \mathrm{W}$, conforme NBR 15220 (ABNT, 2003).

$$
\mathrm{R}\left(\mathrm{m}^{2} \cdot \mathrm{K}\right) / \mathrm{W}=\frac{e}{\lambda}
$$

Onde:

R: resistência térmica do fechamento;

$\lambda$ : condutividade térmica $\left(\mathrm{W} / \mathrm{m} .{ }^{\circ} \mathrm{C}\right)$;

e: espessura do material (m).

A transmitância térmica (U), descrita na equação 3, é o fluxo de calor transmitido por unidade de área e diferença de temperatura. Sendo U inversamente proporcional a RT, quanto maior a resistência do fechamento, menor será a transmitância.

$$
\mathrm{U}\left(\mathrm{m}^{2} \cdot \mathrm{K} / \mathrm{W}\right)=\frac{1}{\mathrm{R}_{\mathrm{T}}}
$$

Onde:

U: transmitância térmica;

RT: resistência térmica total $\left(\mathrm{m}^{2} . \mathrm{K} / \mathrm{W}\right)$.

Para as situações 1 e 2 foram utilizadas as equações anteriores, e seus resultados podem ser observados no quadro 1 .

Quadro 1 - Resistência térmica total e transmitância dos fechamentos

\begin{tabular}{|c|c|c|c|c|}
\hline \multirow{2}{*}{ Fechamento } & \multicolumn{2}{|c|}{$\begin{array}{c}\text { Situação 1 - } \\
\text { Materialidade Orginal }\end{array}$} & \multicolumn{2}{c|}{$\begin{array}{c}\text { Situação 2 - Isolamento } \\
\text { Térmico }\end{array}$} \\
\cline { 2 - 5 } & $\mathrm{RT}\left(\mathrm{m}^{2} \mathrm{k} / \mathrm{w}\right)$ & $\mathrm{U}\left(\mathrm{w} / \mathrm{m}^{2} \mathrm{k}\right)$ & $\mathrm{RT}\left(\mathrm{m}^{2} \mathrm{k} / \mathrm{w}\right)$ & $\mathrm{U}\left(\mathrm{w} / \mathrm{m}^{2} \mathrm{k}\right)$ \\
\hline Parede & 0,386 & 2,591 & 1,466 & 0,682 \\
\hline Cobertura & 0,557 & 1,796 & 3,457 & 0,289 \\
\hline Vigas/grautes & 0,299 & 3,34 & 1,549 & 0,65 \\
\hline Janela & 0,173 & 5,79 & 0,67 & 1,5 \\
\hline
\end{tabular}

Fonte: Dos autores (2019). 


\subsection{Fluxo Térmico}

O fluxo térmico (q) representa uma taxa de calor que é transferida para dentro dos ambientes através de suas superfícies, para fechamentos opacos utilizou-se a equação 4 . Este fluxo considera a absorvida de das cores, incidência solar e diferenças de temperaturas entre os meios.

$$
\mathrm{q}_{\mathrm{FO}}\left(\mathrm{W} / \mathrm{m}^{2}\right)=\mathrm{U}\left(\alpha * I * \mathrm{R}_{\mathrm{se}}+\Delta \mathrm{t}\right)
$$

Onde:

$\mathrm{q}_{\mathrm{FO}}$ : fluxo térmico para fechamento opaco;

$\mathrm{U}$ : transmitância térmica $\left(\mathrm{W} / \mathrm{m}^{2} \mathrm{k}\right)$, valores verificados no Quadro 1;

$\alpha$ : absorvida de da superfície externa do fechamento, neste caso utilizouse o valor de 0,67 referente a cor azul imperial utilizada nas fachadas; e 0,745 para o telhado, cor concreto.

I: Índice de radiação solar $\left(\mathrm{W} / \mathrm{m}^{2}\right)$, utilizam-se os valores críticos correspondentes à posição geográfica das fachadas no dia 22 de dezembro e latitude $30^{\circ}$;

$\mathrm{R}_{\mathrm{se}}$ : resistência superficial externa, neste caso com fluxo de calor descendente, valor de $0,04 \mathrm{~m}^{2} . \mathrm{K} / \mathrm{W}$ (ABNT, 2003);

$\Delta t$ :variação de temperatura entre meio externo e interno, cujos valores foram considerados de $34^{\circ} \mathrm{C}$ e $24^{\circ} \mathrm{C}$ respectivamente.

Para fechamentos translúcidos, neste caso as janelas de vidro, utilizouse a equação 5 .

$$
\mathrm{q}_{\mathrm{FT}}\left(\mathrm{W} / \mathrm{m}^{2}\right)=\mathrm{q}_{\mathrm{A}}+\mathrm{q}_{\mathrm{S}}
$$

Onde:

$\mathrm{q}_{\mathrm{FT}}$ : fluxo térmico para fechamento translúcido;

$$
\mathrm{q}_{\mathrm{A}}=\mathrm{U} * \Delta \mathrm{t}
$$

$\mathrm{q}_{\mathrm{S}}=\mathrm{F}_{\mathrm{S}}$ * I, onde o fator solar (FS) é a quantidade de calor que o vidro transmite o ambiente interno, dada pelo fabricante. Para o vidro simples $3 \mathrm{~mm}$, $\mathrm{FS}=87 \%$. Para o vidro duplo insulado de controle solar neutro $\mathrm{FS}=27 \%$.

\subsection{Carga Térmica}

A quantidade total de calor que entra no ambiente é chamada de carga térmica, esta considera os fechamentos e suas áreas de contribuição. Além da carga dos ambientes e suas materialidades, este estudo considerou também 
uma carga de $150 \mathrm{~W}$ para cada ocupante e/ou equipamentos situados em cada cômodo, conforme equação 6.

$$
\mathrm{Q}(\mathrm{W})=\sum_{q 0} * \mathrm{~A}+\sum_{q t} * A+150 * P
$$

Onde:

Q: carga térmica total do ambiente;

$\mathrm{q}_{\mathrm{o}}$ : fluxo térmico de fechamento opaco $\left(\mathrm{W} / \mathrm{m}^{2}\right)$;

A: área de contribuição de determinado fechamento $\left(\mathrm{m}^{2}\right)$;

$\mathrm{q}_{\mathrm{t}}$ : fluxo térmico de fechamento translúcido $\left(\mathrm{W} / \mathrm{m}^{2}\right)$;

P: soma de ocupantes e equipamentos, considerando 2 pessoas e 2 equipamentos em cada dormitório, mais 2 equipamentos na sala.

Com o valor da carga térmica total relacionado ao custo do $\mathrm{Kw} / \mathrm{h}$, de $\mathrm{R} \$ 0,62$ em maio, para a cidade de Lajeado, foi possível calcular a diferença de consumo energético e a economia de valor entre as duas situações estudadas para os quatro apartamentos. Além disso, calculou-se a diferença no sistema de climatização artificial para os ambientes com isolamento e sem isolamento, deste modo cada $1 \mathrm{~W}$ de carga térmica equivale a 3,412 British Thermal Unit (BTUs), unidade de energia utilizada para a comercialização de ar condicionado.

\section{RESULTADOS E DISCUSSÕES}

O posicionamento geográfico em relação algumas acomodações fazem com que a contribuição térmica pelo fluxo de calor seja maior em algumas fachadas do que em outras. Nos gráficos a seguir podemos verificar melhorias em questões de isolamento térmico com redução no consumo de energia.

O gráfico 1 apresenta a carga térmica total do apartamento Sul - Oeste de 3 dormitórios, para parede, janela e cobertura, assim como para pessoas e equipamentos com seu porcentual relacionado à carga transmitida. A maior contribuição de calor aconteceu pela janela ficando num total de 39,3\% e a segunda maior nas paredes com $26,7 \%$. 
Gráfico1-Carga térmica total da Fachada Sul-Oeste sem melhorias

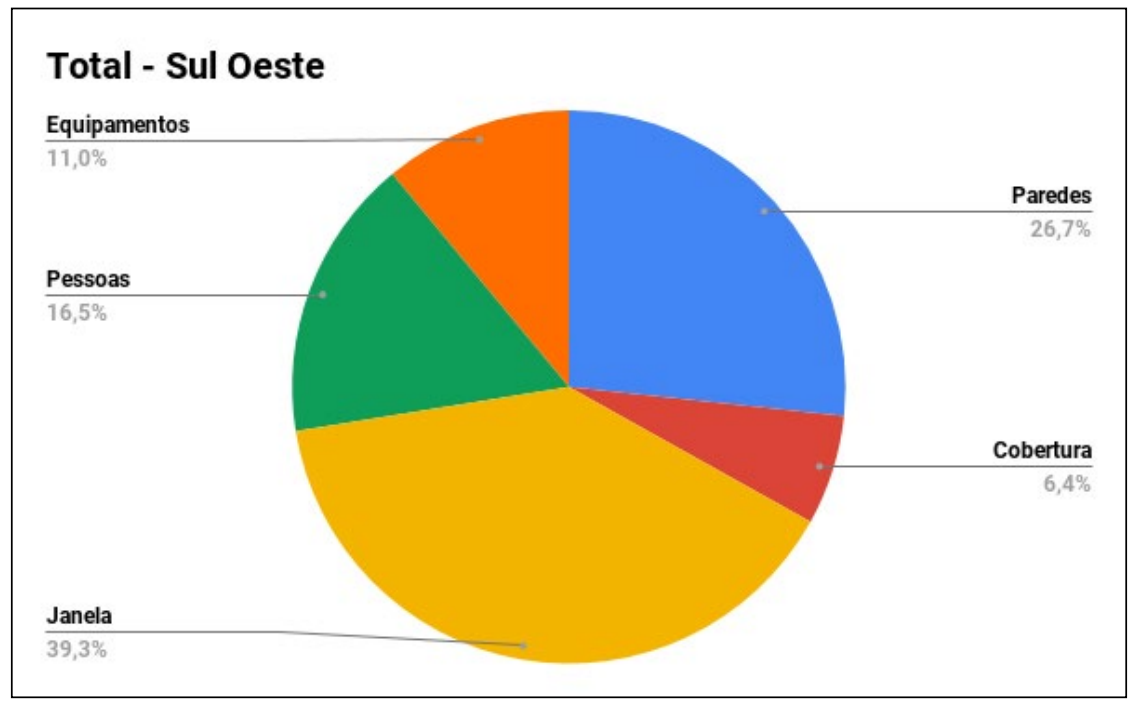

Fonte: Dos autores (2019).

Com a aplicação de isolamento térmico, que utilizou na cobertura a telha sanduíche de EPS e aço galvanizado, nas paredes placas de EPS e na janela o vidro duplo insulado, conseguimos ver no gráfico 2 , uma diminuição de $14,8 \%$ para a carga transmitida pelas janelas e $16,3 \%$ pelas paredes.

Gráfico 2 - Carga térmica total da Fachada Sul-Oeste com melhorias

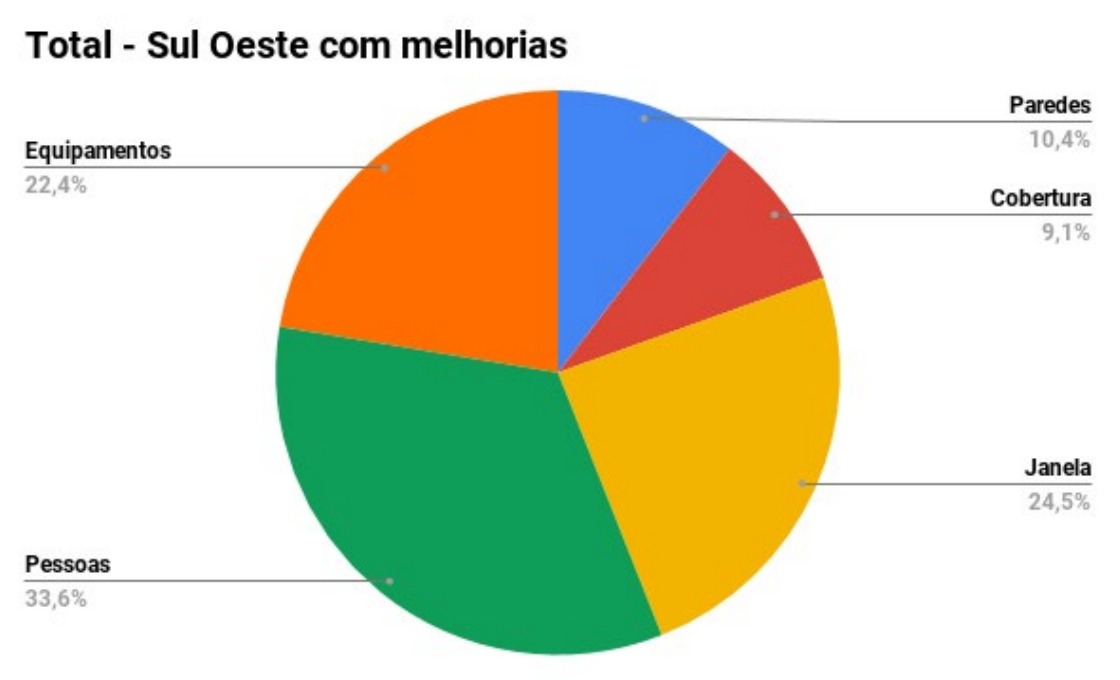

Fonte: Dos autores (2019). 
Os gráficos 3 a 6 trazem as diferenças nos percentuais de carga térmica em cada cômodo do apartamento Sul - Oeste, separadamente. À esquerda estão as cargas sem isolamento térmico, e à direita com isolamento térmico. Percebe-se que na situação sem isolamento as maiores cargas transmitidas são pela janela e paredes, já na situação com isolamento estas cargas diminuem, deixando equipamentos e pessoas em primeiro plano.

Gráfico 3 - Carga térmica total do Dormitório1 sem e com melhorias

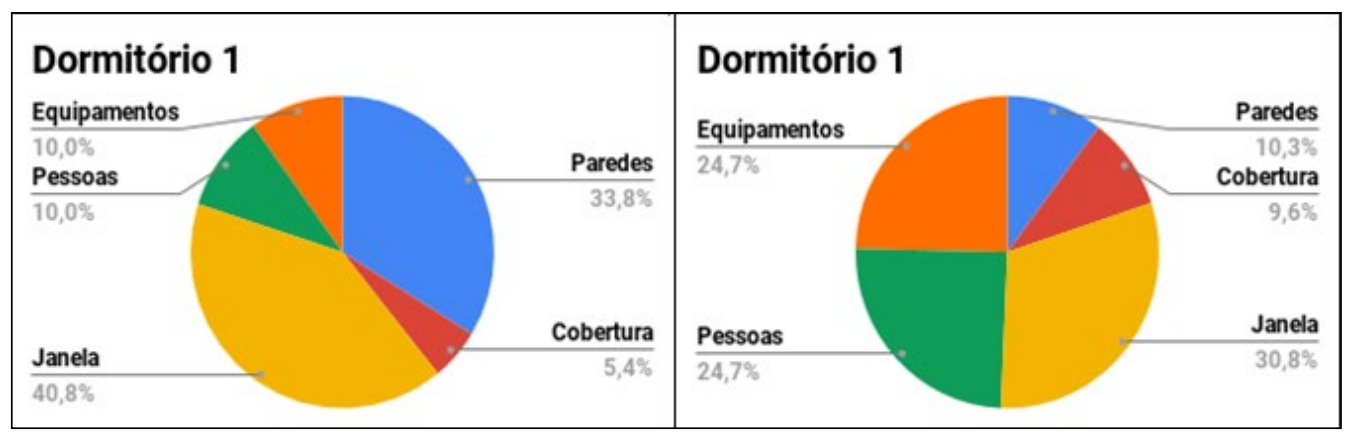

Fonte: Dos autores (2019).

Gráfico 4 - Carga térmica total do Dormitório 2 sem e com melhorias

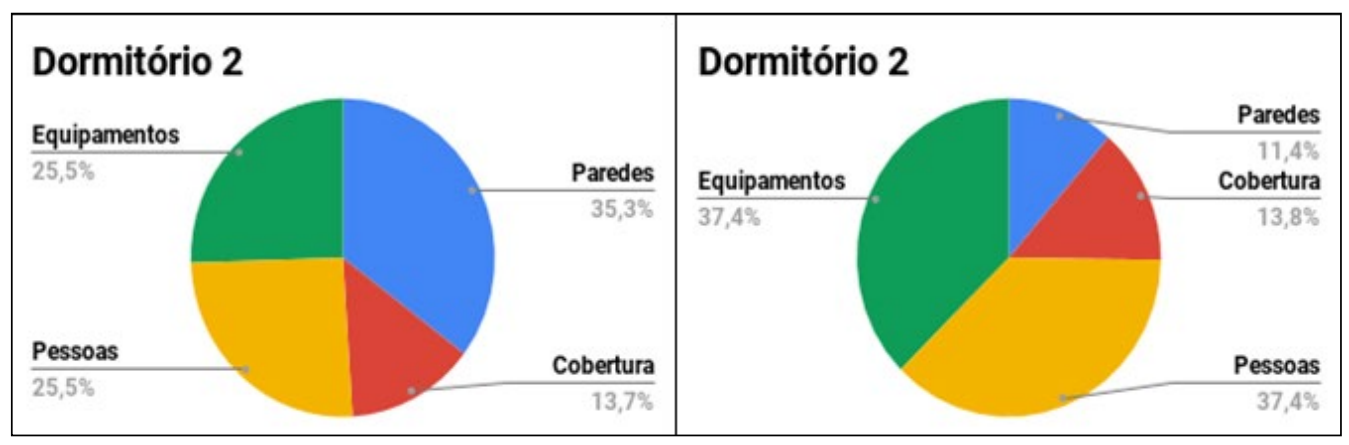

Fonte: Dos autores (2019). 
Gráfico 5 - Carga térmica total do Dormitório 3 sem e com melhorias

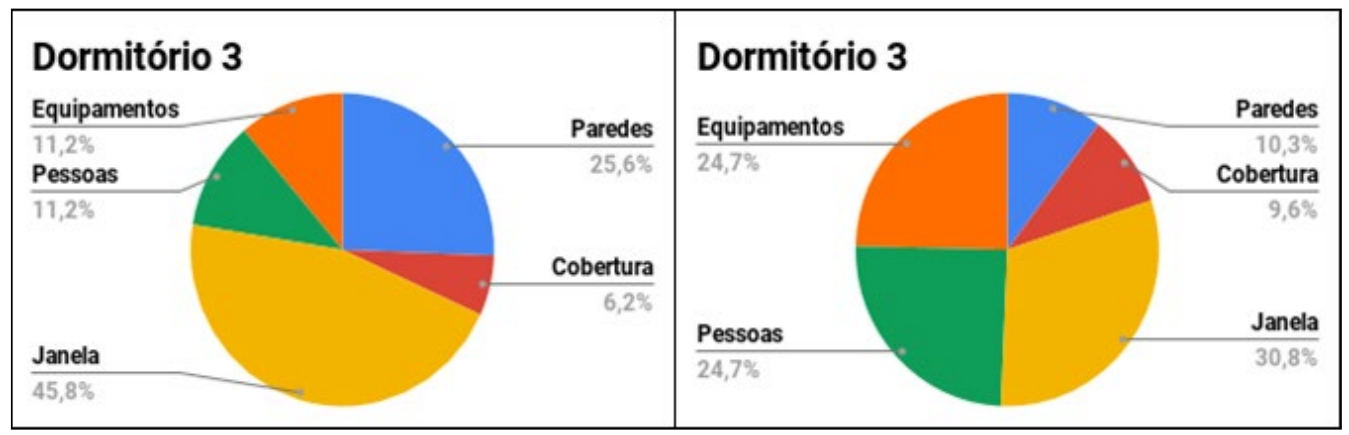

Fonte: Dos autores (2019).

Gráfico 6 - Carga térmica total da Sala sem e com melhorias

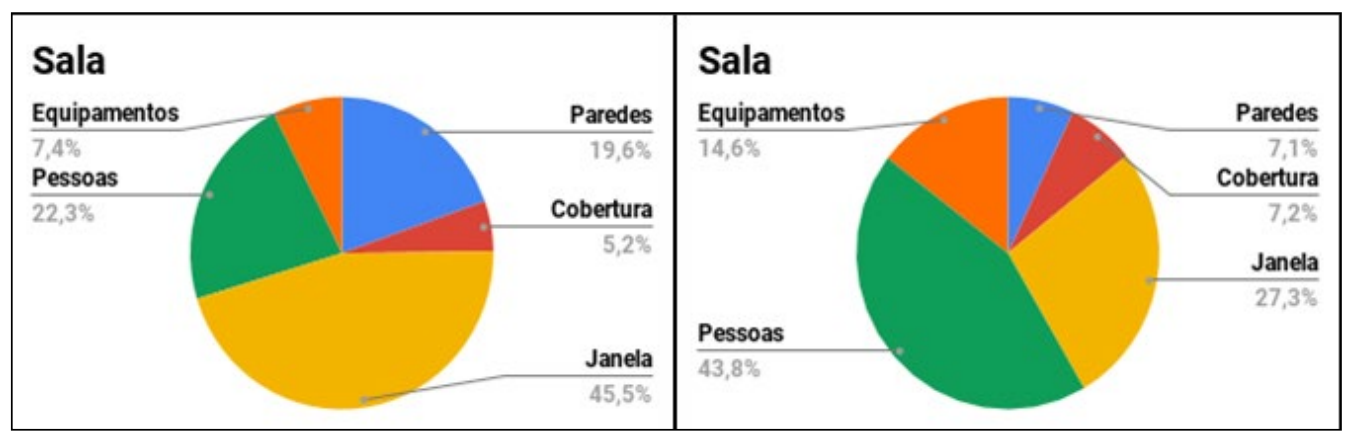

Fonte: Dos autores (2019).

O fator solar (FS) do vidro simples utilizado no projeto é 0,87 , isso significa que $87 \%$ da radiação solar (quantidade de calor) com incidência sobre o vidro entram no ambiente, como utilizamos para possíveis melhorias o vidro duplo insulado que possui seu FS de 0,27, conseguimos ver nos gráficos as melhorias significativas, diminuindo até $40 \%$ no gráfico 6 .

As placas de EPS, moldadas a partir do poliestireno expandido de alta densidade, utilizadas nas paredes, tem como objetivo aumentar o isolamento térmico, proporcionando um maior conforto térmico da edificação. Prova-se um material muito eficaz diminuindo a carga térmica das paredes em até $70 \%$, conforme gráfico 4 . $\mathrm{O}$ mesmo se trata de um material leve, versátil e possui baixa geração de resíduos ao término da utilização.

Para os demais apartamentos, foi calculado apenas a carga térmica total das áreas de vivência, sem dividir por cômodos, como nos gráficos 1 a 6 acima analisados. Os gráficos 7, 8 e 9, apresentam a redução de contribuição térmica das paredes, da janela e da cobertura dos mesmos, o que também se deve ao 
dimensionamento dos materiais de maior eficiência para diminuição da carga térmica total, diminuindo assim a transferência de calor do ambiente externo para o interno. Proporcionando um maior conforto térmico para os ocupantes da edificação, diminuindo o calor gerado pelo mesmo e evitando um maior consumo energético também. À esquerda de cada gráfico está a situação sem isolamento, e à direita a situação com isolamento térmico.

Gráfico 7- Carga térmica do Apartamento Norte - Leste 2 dormitórios sem e com melhorias

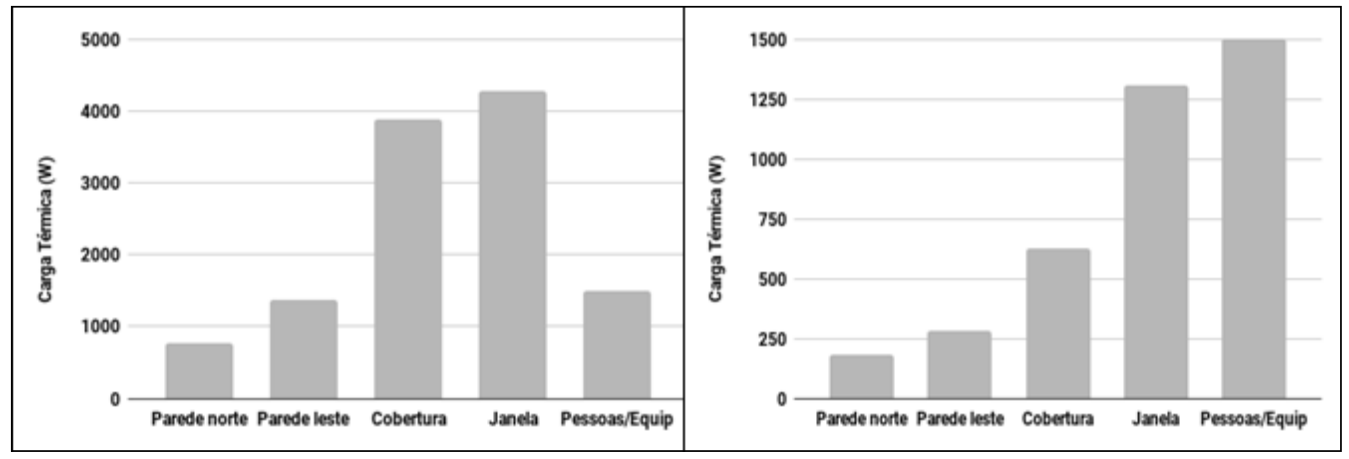

Fonte: Dos autores (2019).

Gráfico 8 - Carga térmica do Apartamento Oeste com 2 dormitórios sem e com melhorias

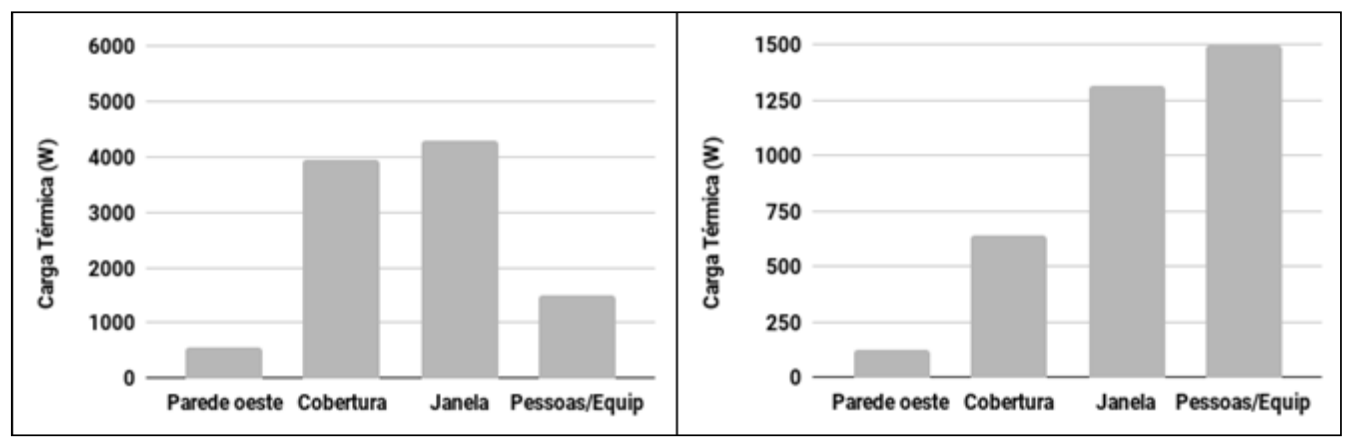

Fonte: Dos autores (2019). 
Gráfico 9 - Carga térmica do Apartamento Leste com 1 dormitório sem e com melhorias

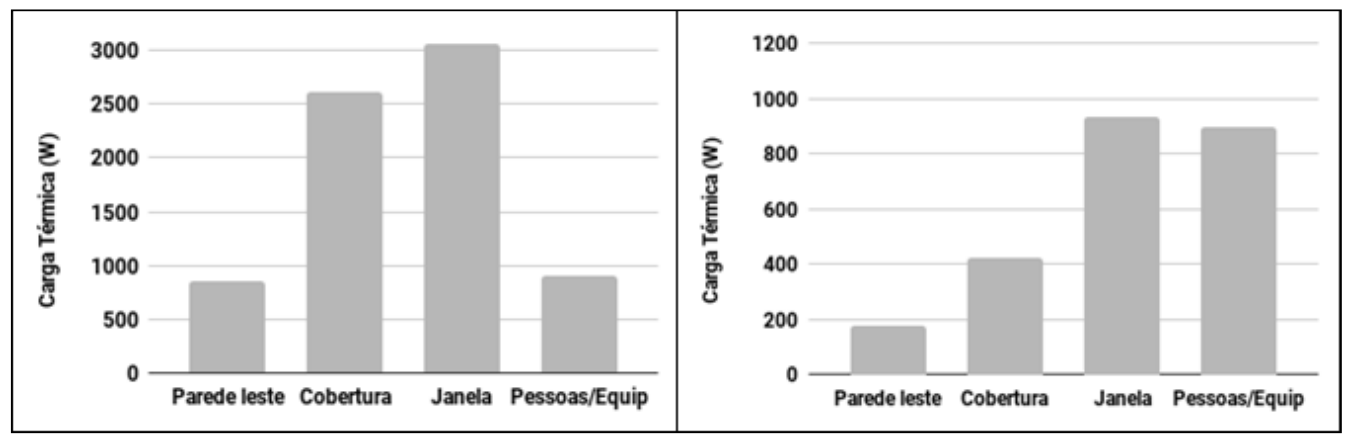

Fonte: Dos autores (2019).

Nos gráficos 7 a 9 também é possível observar a considerável redução da carga térmica transmitida pela telha sanduíche, podendo chegar em quase $80 \%$ e oferecendo uma resistência nas trocas constantes de calor interno e externo da edificação.

O quadro 2, mostra o consumo de climatização artificial, indicando a carga térmica total dos ambientes do apartamento detalhado nos gráficos $1 \mathrm{a}$ 6. Quando comparados os valores com e sem isolamento térmico, consegue-se perceber claramente que com os materiais isolantes além de ter reduzido a carga térmica total, reduziu também o consumo energético. Fez-se a comparação apenas do apartamento Sul - Oeste de 3 dormitórios, e apenas o dormitório 2 não apresentou uma diferença significava, devido à falta de janela na posição solar estudada. Os outros dois dormitórios e a sala geraram uma economia de $50 \%$.

A sigla BTUs, que significa British Thermal Unit (Unidade térmica britânica) são as unidades de resistência para aparelhos de climatização artificial disponíveis no mercado, por meio desta resistência obtêm-se a potência de refrigeração do aparelho. Assim, quanto maior a potência, maior o conforto térmico e consequentemente, maior o consumo de energia. Desta forma tomou-se como referência o valor calculado de carga térmica total em Wats para cada ambiente e converteu-se em BTUs. Com a quantidade de BTUs pôde-se comparar o gasto econômico dos ambientes com e sem isolamento térmico, conforme Quadro 2. Utilizou-se o valor do $\mathrm{Kw} / \mathrm{h}$ para a cidade de Lajeado em maio de 2019. 
Quadro 2-Consumo de climatização artificial

\begin{tabular}{|c|c|c|c|c|c|c|c|c|}
\hline \multicolumn{2}{|c|}{ Ambiente } & \multirow{2}{*}{\begin{tabular}{|c|}
$\begin{array}{c}\text { Carga } \\
\text { Térmica Total } \\
\text { (W) }\end{array}$ \\
2998,84 \\
\end{tabular}} & \multirow{2}{*}{\begin{tabular}{|c|}
$\begin{array}{c}\text { Climatização } \\
\text { (BTUs) }\end{array}$ \\
10232,04 \\
\end{tabular}} & \multirow{2}{*}{\begin{tabular}{|c|}
$\begin{array}{c}\text { BTUs } \\
\text { para } \\
\text { compra }\end{array}$ \\
12000 \\
\end{tabular}} & \multirow{2}{*}{$\begin{array}{l}\text { Valor } \\
\mathrm{Kw} / \mathrm{h}\end{array}$} & \multirow{2}{*}{$\begin{array}{c}\begin{array}{c}\text { Horas/mês } \\
8 \mathrm{~h} * 20 \text { dias }\end{array} \\
160 \\
\end{array}$} & \multirow{2}{*}{\begin{tabular}{|c|}
$\begin{array}{c}\text { TOTAL R\$ SEM } \\
\text { ISOLAMENTO }\end{array}$ \\
$\mathrm{R} \$ 297,48$ \\
\end{tabular}} & \multirow{2}{*}{$\begin{array}{l}\text { TOTAL R\$ COM } \\
\text { ISOLAMENTO }\end{array}$} \\
\hline \multirow{2}{*}{ Domitório 1} & Sem isolam & & & & & & & \\
\hline & Com isolam & 1283,53 & 4379,39 & 7000 & $\mathrm{R} \$ 0,62$ & 160 & - & $\mathrm{R} \$ 127,33$ \\
\hline \multirow{2}{*}{ Domitório 2} & Sem isolam & 1176,19 & 4013,14 & 7000 & $R \$ 0,62$ & 160 & $\mathrm{R} \$ 116,68$ & - \\
\hline & Com isolam & 802,36 & 2737,64 & 7000 & $\mathrm{R} \$ 0,62$ & 160 & - & $\mathrm{R} \$ 79,59$ \\
\hline \multirow{2}{*}{ Domitório 3} & Sem isolam & 2674,93 & 9126,87 & 12000 & $R \$ 0,62$ & 160 & $R \$ 265,35$ & - \\
\hline & Com isolam & 1216,57 & 4150,95 & 7000 & $\mathrm{R} \$ 0,62$ & 160 & - & $R \$ 120,68$ \\
\hline \multirow{2}{*}{ Sala } & Sem isolam & 4037,72 & 13776,7 & 15000 & $\mathrm{R} \$ 0,62$ & 160 & $\mathrm{R} \$ 400,54$ & - \\
\hline & Com isolam & 2055,29 & 7012,67 & 9000 & $R \$ 0,62$ & 160 & - & $R \$ 203,88$ \\
\hline \multicolumn{6}{|c|}{$1 \mathrm{~W}=3,412 \mathrm{BTU} / \mathrm{h}$} & TOTAL: & $\mathrm{R} \$ 1.080,06$ & $\mathrm{R} \$ 531,49$ \\
\hline
\end{tabular}

Fonte: Dos autores (2019).

\section{CONSIDERAÇÕES FINAIS}

Conforme especificado por Goulart (1993), o desempenho das edificações passa pelo estudo da climatologia, ou seja, se a utilização de EPS nas paredes com maior incidência solar da construção for pensada ainda na fase de projeto, podem-se evitar maiores gastos em aparelhos de ar condicionado e consequentemente, obtêm-se um maior conforto térmico para os usuários.

Através deste estudo confirma-se o que Oliveira (2015) fala sobre a arquitetura oferecer conforto e melhores condições de vida ao homem, pois a diferença de desempenho entre os ambientes com e sem isolamento térmico é considerável. Desta forma, o auxílio de um profissional capacitado se faz imprescindível na busca por um bom desempenho térmico das edificações e menor consumo energético, citando não apenas o menor custo mensal em contas de energia, mas também pensando no meio ambiente e no conceito de sustentabilidade.

\section{REFERÊNCIAS}

ASSOCIAÇÃO BRASILEIRA DE NORMAS TÉCNICAS. NBR 15220:

Desempenho Térmico de edificações. Rio de Janeiro: Abnt Editora, 2003.

GOULART, Solange V. G Dados climáticos para avaliação de desempenho térmico de edificações em Florianópolis. Universidade Federal de Santa Catarina. Florianópolis-SC. 1993

OLIVEIRA, Patrícia Lima de; SOARES, Raquel Gomes; SANTOS, Silvio Xavier. Desempenho térmico das edificações: estudo comparativo entre o telhado verde e outros tipos de coberturas. Revista Petra, Belo Horizonte (MG) v. 2, n. 1, p.36-55, jan. 2016. 